\title{
EDUCAÇÃO AMBIENTAL NA ESCOLA RURAL: CONHECIMENTOS E FERRAMENTAS DE APRENDIZADO ACERCA DOS MAMÍFEROS DO CERRADO
}

\author{
José Neiva Mesquita-Neto ${ }^{1}$ \\ Francielle Pinto Ribeiro² \\ Gleyce Alves Machado²
}

Resumo: Este estudo objetivou utilizar ferramentas da Educação Ambiental para difusão de conhecimentos sobre mamíferos do Cerrado, bem como o usar moldes de pegadas de mamíferos como materiais pedagógicos, facilitadores do aprendizado e potencializadores para a inclusão social, e provocar reflexões nos estudantes sobre os efeitos de suas próprias ações sobre o ecossistema que o cerca e assim contribuir na formação de cidadãos ambientalmente responsáveis. O presente trabalho foi desenvolvido com alunos do $6^{\circ}$ ao $9^{\circ}$ ano do ensino fundamental. A confecção dos moldes foi feita a partir de contramoldes feitos de gesso coletados a partir rastros de mamíferos em campo localizados em fragmentos de Cerrado da região. Com a realização deste estudo, foi possível utilizar os moldes e contramoldes de pegadas como materiais pedagógicos. Conclui-se que estes modelos facilitaram o aprendizado e a inclusão social. Pode-se inferir ainda que este projeto possibilitou reflexões críticas entre os alunos e contribui para a formação de cidadãos ambientalmente responsáveis.

Palavras-chave: Rastros; Material Pedagógico; Biodiversidade; Conservação; Inclusão Social.

${ }^{1}$ Universidade Federal de Minas Gerais, Instituto de Ciências Biológicas, PPG em Biologia Vegetal. E-mail: jneiva.bio@gmail.com

2 Universidade Federal de Goiás, Regional Catalão, Departamento de Ciências Biológicas. E-mail: machadoga@gleyce.bio.br. 


\section{Introdução}

As áreas mais importantes para preservar a biodiversidade na Terra são chamadas de "hotspots". De acordo com Myers et al. (2000) no Brasil existem dois hotspots de biodiversidade: a Mata Atlântica e o Cerrado. Estes biomas lideram a lista dos que apresentam maior proporção de espécies endêmicas ameaçadas, destes $34 \%$ são de mamíferos endêmicos da Mata Atlântica e $29 \%$ dos endêmicos do Cerrado. O Cerrado está sendo destruído com uma velocidade muito superior à capacidade de a comunidade científica levantar o conhecimento necessário para sua proteção e conservação (BENITES; MAMEDE, 2008). Um fato preocupante, é que de acordo com estudos de Machado (2004) o bioma Cerrado deverá ser totalmente destruído no ano de 2030, caso as tendências de ocupação continuem.

O Cerrado possui a mais rica flora dentre as savanas do mundo, mais de 7.000 espécies, com alto nível de endemismo (KLINK; MACHADO, 2005). O Estado de Goiás é ocupado por cerca de 95\% de Cerrado, sendo também um dos Estados que mais contribui para os altos índices de desmatamento ocorridos neste bioma.

Feinsinger (2004) enfatiza que a prática da conservação da biodiversidade e do ambiente como um todo depende do esforço não somente dos profissionais especializados para este fim, mas também e, principalmente, da colaboração das comunidades locais. Deste modo, a Educação Ambiental (EA) atua como ligação entre as ciências e as comunidades, intercalando-se como uma ferramenta útil à biologia da conservação e forte aliada para o alcance de sociedades sustentáveis (BENITES; MAMEDE, 2008).

A necessidade de criação de uma educação voltada ao ambiente rural é evidente, já que a educação transmitida na zona rural é a mesma da urbana. Necessita-se de um enfoque da escola para a cultura da própria região, que aos poucos vai morrendo no decorrer das gerações (DAMASCENO; BEZERRA, 2004). Historicamente os ambientes naturais são considerados locais de domínio do selvagem, do ameaçador e do visualmente desagradável, assim associou-se o progresso a devastação e dominação do ambiente original. Deste modo, a cultura presente no meio rural é desvalorizada e as pessoas de criação urbana são consideradas mais civilizadas (CARVALHO, 2008).

A década de 60 foi marcada pela descoberta dos efeitos danosos causados pelo modelo de desenvolvimento econômico adotado pelos países ricos (CARVALHO, 2008). De acordo com a FEHIDRO, projetos com enfoque na Educação Ambiental devem ser fundamentados em recomendações e diretrizes estabelecidas pelas grandes conferencias internacionais. A primeira conferência que tratou especificamente do tema foi a de Tbilisi, na Geórgia, em 1977, na qual foi formulado o conceito, princípios e diretrizes da Educação Ambiental e demonstrado a sua importância na resolução de problemas ambientais (TRIVELATO, 2001). 
A segunda conferência internacional com o tema "Educação e Conscientização Pública para Sustentabilidade", aconteceu em 1997 em Tessalonic, Grécia, que adiciona a EA uma visão sustentável de uso dos recursos ambientais. Sob o aspecto federal destacam-se a Lei no 9795, de 27/4/1999, que institui a Política Nacional de EA e o Decreto $n^{\circ} 4.281$ de 25/6/02, que a regulamentou. O Artigo $1^{\circ}$ da Lei afirma que "Entendem-se por EA os processos por meio dos quais o indivíduo e a coletividade constroem valores sociais, conhecimentos, habilidades, atitudes e competências voltadas para a conservação do meio ambiente, bem de uso comum do povo, essencial a sadia qualidade de vida e sua sustentabilidade. O Artigo $2^{\circ}$ dispõe que "A EA é um componente essencial e permanente da educação nacional, devendo estar presente, de forma articulada, em todos os níveis e modalidades do processo educativo, em caráter formal e não-formal. Ainda segundo recomendações da FEHIDRO, trabalhos sobre EA devem possuir caráter regionalista focando assim a relação entre as comunidades locais e o ambiente em que vivem, já que é a partir dos problemas ambientais enfrentados pela comunidade tradicional que e EA deve formular possíveis soluções para resolução dos mesmos, despertando assim o interesse sob as pessoas daquele local.

De acordo com Carvalho (2008), o homem é fruto do ambiente que o cerca, os conhecimentos prévios do aluno do campo não devem ser desconsiderados, pelo contrário, devem ser explorados e aperfeiçoados para que seja formado um cidadão crítico capaz de transformar e refletir sobre suas ações no ambiente, pois contribuir para a existência de uma atitude ecológica possível é a principal aspiração da EA. Trivelato (2001) afirma que as Ciências Naturais principalmente a Ecologia foram as principais precursoras da EA por focarem na compreensão das inter-relações de homem e o meio biofísico, por isso as ciências biológicas tem seu mérito na formação de um sujeito ambientalmente correto, mesmo que indiretamente.

Dentre as inúmeras espécies presentes no Cerrado, o interesse em se trabalhar com os mamíferos, ocorre uma vez que estes são componentes essenciais nas cadeias alimentares, ocupando desde a base (Ex. roedores) até o topo (Ex. carnívoros), sendo um dos principais animais afetados pelas ações antrópicas, tais como a fragmentação de habitats, atropelamentos, caça, introdução de espécies exóticas, desmatamento e tráfico de animais (SCOSS et al., 2004; GRELLE; PAGLIA; SILVA, 2006; COOLEY et al., 2009). Estima-se que existam em todo o mundo, cerca de 4.250 espécies de mamíferos, sendo que no Brasil, ocorrem 652 dessas espécies. Esses números indicam o Brasil como possuidor da maior riqueza de mamíferos de toda a região neotropical (CARVALHO Jr.; LUZ, 2008). Em regiões tropicais a observação de mamíferos em seus ambientes naturais é difícil, devido aos seus hábitos contidos, enquanto que pegadas são facilmente encontradas (FIGUEIRA et al., 2004).

A utilização de pegadas é simples e informativa, pois a partir do seu estudo, muito pode ser deduzido. Esta técnica possibilita conhecer quais animais provavelmente estão presentes, densidades populacionais, domínio vital, assim 
como a responsabilidade por marcas deixadas em árvores (BECKER; DALPONTE, 1999). Berlinck e Lima (2007) acrescentam que a retirada de moldes e contramoldes de pegadas funciona como um complemento ou alternativa para os métodos convencionais de ensino e aprendizado de conceitos de ecologia e de vida silvestre. Sobre este assunto, Becker e Dalponte (1999) fazem uma interessante consideração: "não há quem não experimente, ao ver uma sequência de rastros no campo, a excitação de imaginar de onde teriam vindo, para onde seguiam e o que sucedeu nos pontos em que várias pegadas se misturam".

Diante do exposto, este estudo teve como objetivo utilizar a EA como ferramenta para difusão de conhecimentos sobre mamíferos do Cerrado. Bem como o uso de moldes de pegadas como materiais pedagógicos, facilitadores do aprendizado e potencializadores para a inclusão social. E, além disso, visou provocar reflexões nos estudantes sobre os efeitos de suas próprias ações sobre o ecossistema que o cerca e assim contribuir na formação de cidadãos ambientalmente responsáveis.

\section{Metodologia}

\section{Escola campo e público alvo}

O presente trabalho foi desenvolvido com alunos do $6^{\circ}$ ao $9^{\circ}$ ano do ensino fundamental, da escola municipal: "Arminda Rosa de Mesquita" localizada na zona rural do município de Catalão, Goiás.

\section{Aulas expositivas}

Os moldes das pegadas foram usados em sala de aula, para demonstrar a variedade de mamíferos que ainda vivem na região. Além dos moldes, também foram apresentadas imagens, vídeos, slides em DataShow sobre os hábitos e habitats destes mamíferos. Para enfatizar a EA, foram discutidos os fatores responsáveis pela diminuição do número de espécies ao longo do tempo e a necessidade de conservação dos remanescentes vegetais da região para possibilitar a continuidade da sobrevivência dos animais ainda encontrados.

\section{Modelagem das pegadas}

A confecção dos moldes foi feita de contramoldes feitos de gesso coletados a partir rastros de mamíferos em campo localizados em fragmentos de Cerrado da região. A fim de validar as pegadas coletadas, foram consultados manuais de identificação (BECKER; DALPONTE , 1999; CARVALHO JR.; LUZ, 2008). Os moldes foram confeccionados por meio de materiais reciclados (papel e serragem) e agregadores (gesso e cola) formando uma massa rígida e resistente a choques após a secagem, adequada para uso educacional, assim como descrito por Freitas et al. (2008). O processo de manufatura consiste na 
homogeneização de papel, cola, serragem e gesso, até a obtenção de uma mistura modelável. Posteriormente os modelos foram deixados em uma superfície plana para secagem e só então pintados com tinta para artesanato, e em seguida etiquetados com informações contendo o nome popular e cientifico da espécie, local e data de coleta.

\section{Verificação de aprendizagem}

Para auxiliar nas análises sobre os conhecimentos prévios dos alunos e na verificação do aprendizado após as oficinas, foi aplicado um questionário em dois momentos, um antes das atividades (pré-testes), o qual teve como objetivo identificar os conhecimentos dos alunos antecedentes a realização do estudo. O outro momento foi após a intervenção (pós-testes), que avaliou o desenvolvimento de aprendizado e consciência ambiental posterior ao cumprimento do projeto.

Com a finalidade de alcançar os objetivos propostos para este trabalho, as seguintes etapas foram desenvolvidas cronologicamente: (1) Realizou-se visitas ao campo para coletar pegadas de mamíferos ocorrentes na região; (2) Consultou-se guias e manuais disponíveis para identificação das espécies e informações sobre sua biologia; (3) Realizou-se visitas à escola campo para avaliar aspectos físicos, pedagógicos e socioambientais (4) Formulou-se conteúdos condizentes com a realidade educacional e cultural dos estudantes; (4) Os métodos de identificação de mamíferos foram apresentados aos estudantes em forma de oficinas; (5) Utilizou-se os moldes das pegadas em sala de aula para demonstrar a variedade de mamíferos que ainda vivem na região e assim provocar a reflexão das ações antrópicas sobre o Cerrado.

\section{Análise estatística}

A análise estatística foi realizada com auxílio do teste t-Student, a fim de verificar se há diferença significativa entre o desempenho dos alunos no pré e pós-teste $(p<0,05)$.

\section{Resultados e discussão}

No decorrer da execução do projeto foram confeccionados moldes e contra-moldes de rastros de mamíferos ocorrentes na região Sudeste de Goiás. Os rastros utilizados foram provenientes de coletas realizadas em campo (Figura 1), na própria região e da coleção do Laboratório Integrado de Botânica e Zoologia (LIZEB). Foram confeccionados moldes de diversas espécies de mamíferos terrestres. A partir desses moldes foram desenvolvidos os contramoldes, que consistem na impressão em relevo contrária aos moldes, estes foram lixados, pintados e utilizados nas oficinas. Os contra-moldes (Figura 1) foram confeccionados a partir de materiais recicláveis e doados a escola campo, para servir como coleção de referência. 


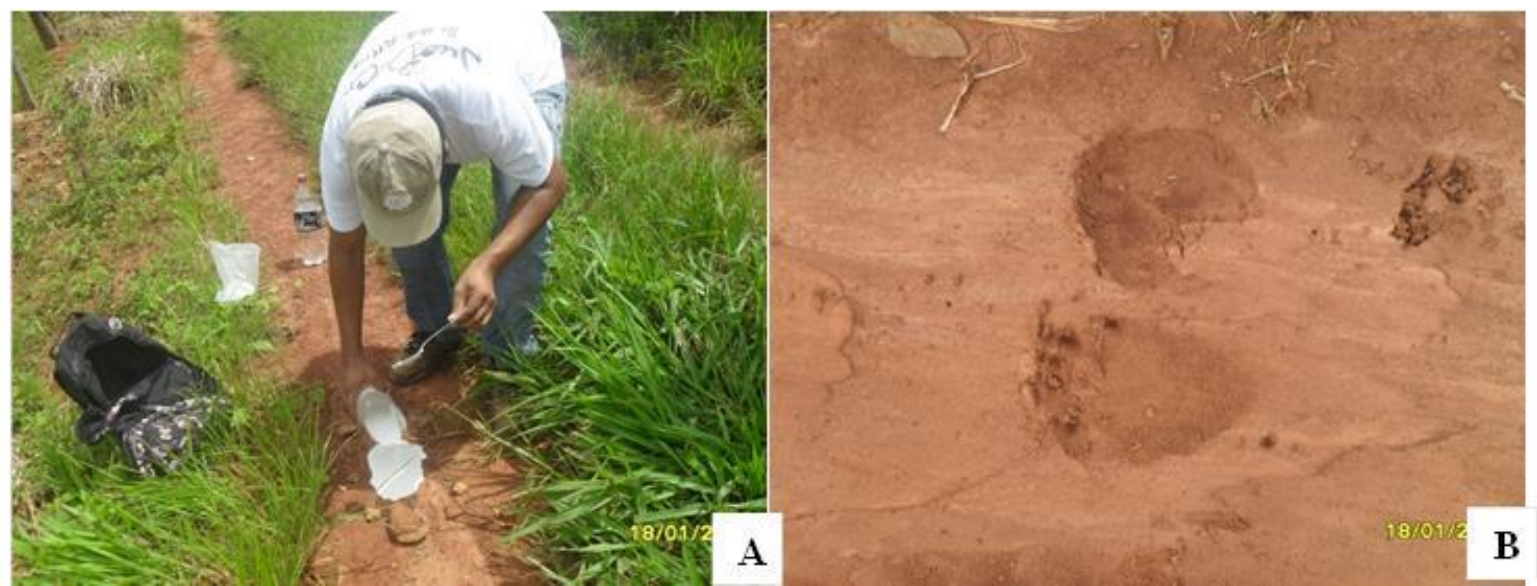

Figura 1: (A) Localização e identificação de rastros de mamíferos terrestes em campo e confecção dos moldes de gesso. (B) Rastros de tamanduá encontrados em campo.

Fonte: Os autores.

Foi realizado ainda um extenso levantamento bibliográfico (BECKER; DALPONTE, 1999; BENITES; MAMEDE, 2008; BERLINCK; LEMOS et al., 2011; LIMA 2007; GRELLE; PAGLIA; SILVA, 2006; SCOSS et al. 2004), de aspectos, características e curiosidades da fauna brasileira, especialmente a ocorrente no Cerrado. Foram encontrados manuais, textos, sites, guias, cartilhas, gibis, que forneceram subsídios na confecção das aulas multimídias e do material didático impresso a ser distribuído aos alunos.

Além disso, foram elaboradas as aulas expositivas, contendo as seguintes informações: Características físicas, distribuição geográfica, habitat, Dieta, reprodução, comportamento e curiosidades, as apresentações continham imagens dos animais e desenhos dos rastros, o que tornou o conteúdo mais atraente e compreensível (Figura 2). As aulas expositivas ainda abordaram assuntos relacionados a conservação e preservação ambiental, prevenção, controle e identificação de casos predação a animais domésticos por mamíferos carnívoros, em especial a onça-parda (Puma concolor). A fragmentação de habitats, diversidade, ecologia, sustentabilidade são questões a serem incluídas nas discussões, de forma secundaria.

No pré-teste, a taxa de acertos foi significativamente maior ( $\mathrm{t}=-3,72$; $p=0,001$ ) de $72,8 \%$, enquanto no pós-teste foi de $84,9 \%$ (Figura 3 ). Foi alcançado um desempenho notável nas questões que tratavam da identificação dos rastros dos mamíferos no pós-teste. Ao analisar os conhecimentos prévios dos alunos (Pré-teste), percebeu-se um bom desempenho, principalmente quando lhes foi indagada a seguinte questão: "Em qual dos ambientes abaixo você acha que a sua escola está inserida", uma vez que todos responderam Cerrado" 


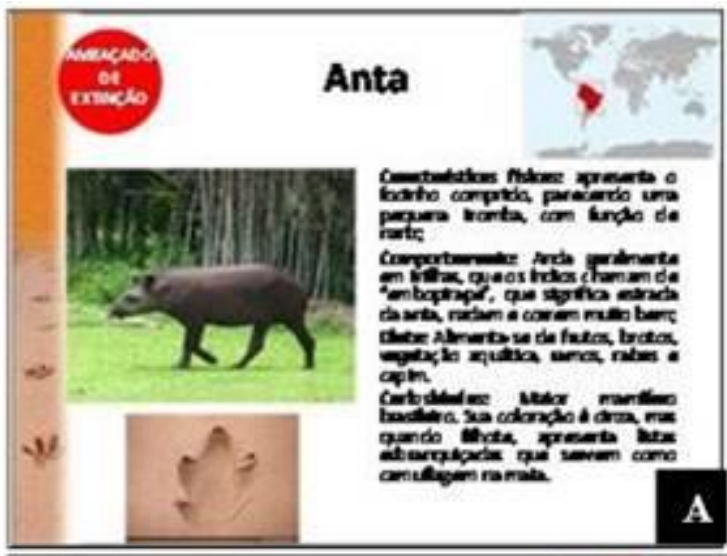

\section{Quanto a predação: onça-pintada}

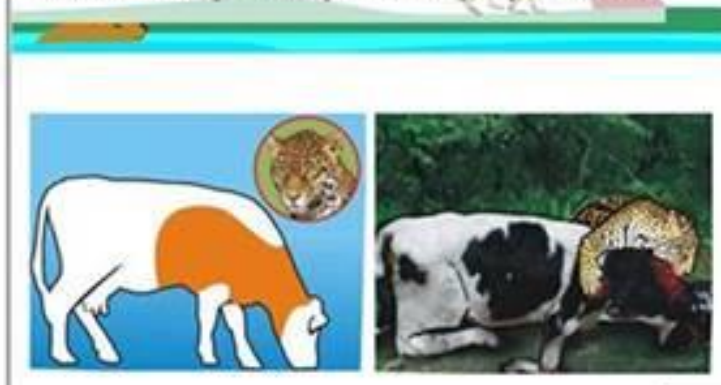

C

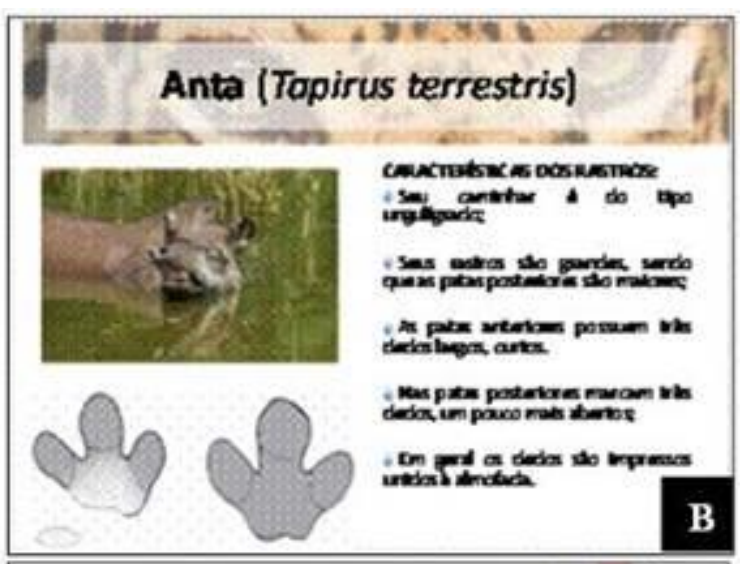

Figura 2: Amostra dos slides utilizados nas apresentações multimídias. A e B contendo as principais características de alguns mamíferos apresentados aos alunos na escola-campo;

(C e D) contendo informações e imagens sobre prevenção de predação de animais domesticos. Fonte: os autores.

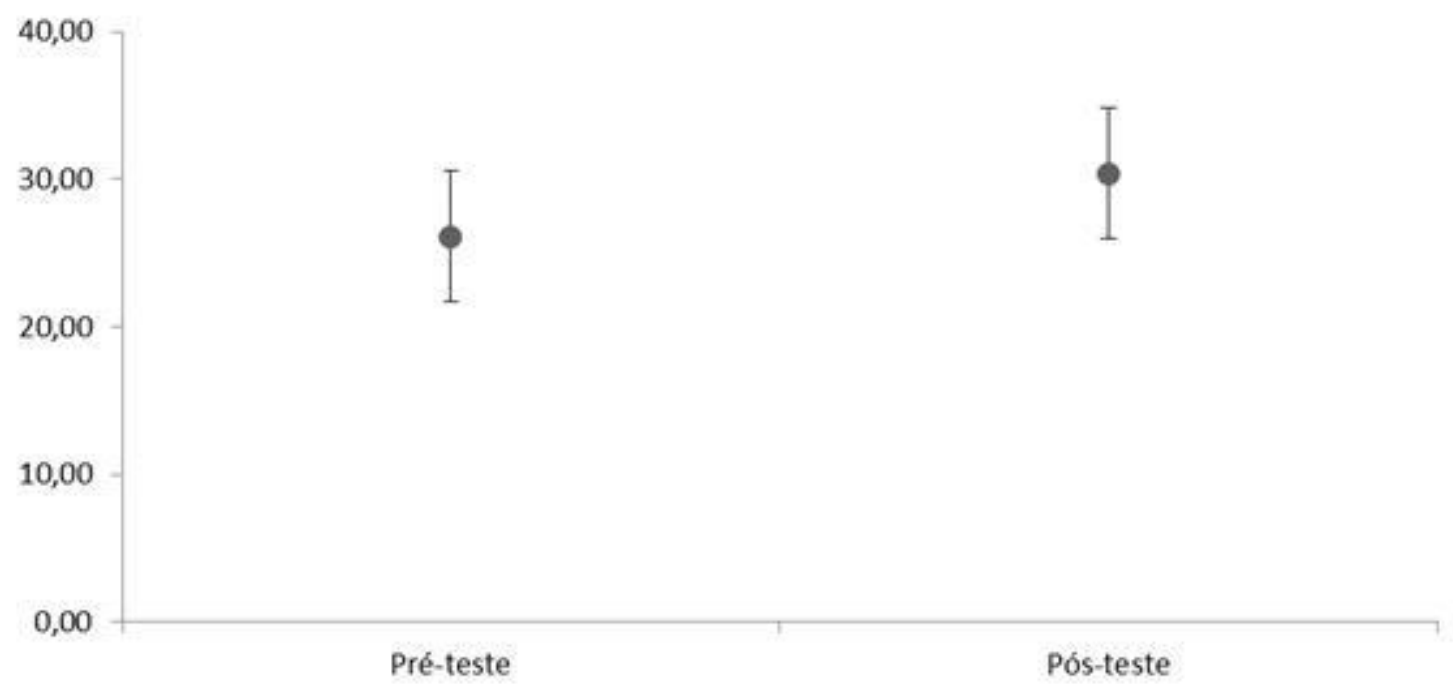

Figura 3: Comparação do desempenho médio dos estudantes no pré e pós-teste, quanto ao questionário aplicado, para cada aluno (1 a 34). Fonte: os autores. 
Apesar da evolução no aprendizado dos alunos por meio da oficina, os estudantes demonstraram conhecimentos prévios relevantes. Isso demonstra que a relação próxima com meio rural e natural, propiciou vivências ímpares aos discentes. O bom desempenho pode ser percebido, tanto nos questionários, quanto no decorrer das palestras. Outro fato que pode ter favorecido os resultados positivos foi observado no comprometimento dos professores da escola campo com relação a Educação Ambiental.

No pós-teste os discentes foram capazes de identificar pelo menos 2 rastros dos 5 rastros apresentados no questionário. Além disso, mais de $50 \%$ dos alunos acertaram todas as questões. Quanto a questão dissertativa de número 10, na qual procurou-se obter informações sobre as principais causas da extinção de alguns animais, observou-se as seguintes explicações: queimadas, habitações, industrialização, desmatamento, destruição e fragmentação de habitats, caça, agricultura extensiva, atropelamentos em rodovias, poluição e a falta de conhecimento.

Além disso, os alunos demonstraram interesse e curiosidade em desvendar os contramoldes apresentados durante as palestras (Figura 4). Os contramoldes foram eficientes como material didático, ilustraram de maneira realista como é o rastro encontrado na natureza. Além disso, por terem sido confeccionados em cores diferentes, foram visivelmente atraentes aos alunos. $O$ fato dos contra moldes serem de material rígido e ao mesmo tempo leve possibilitou o fácil manuseio por todos os envolvidos.

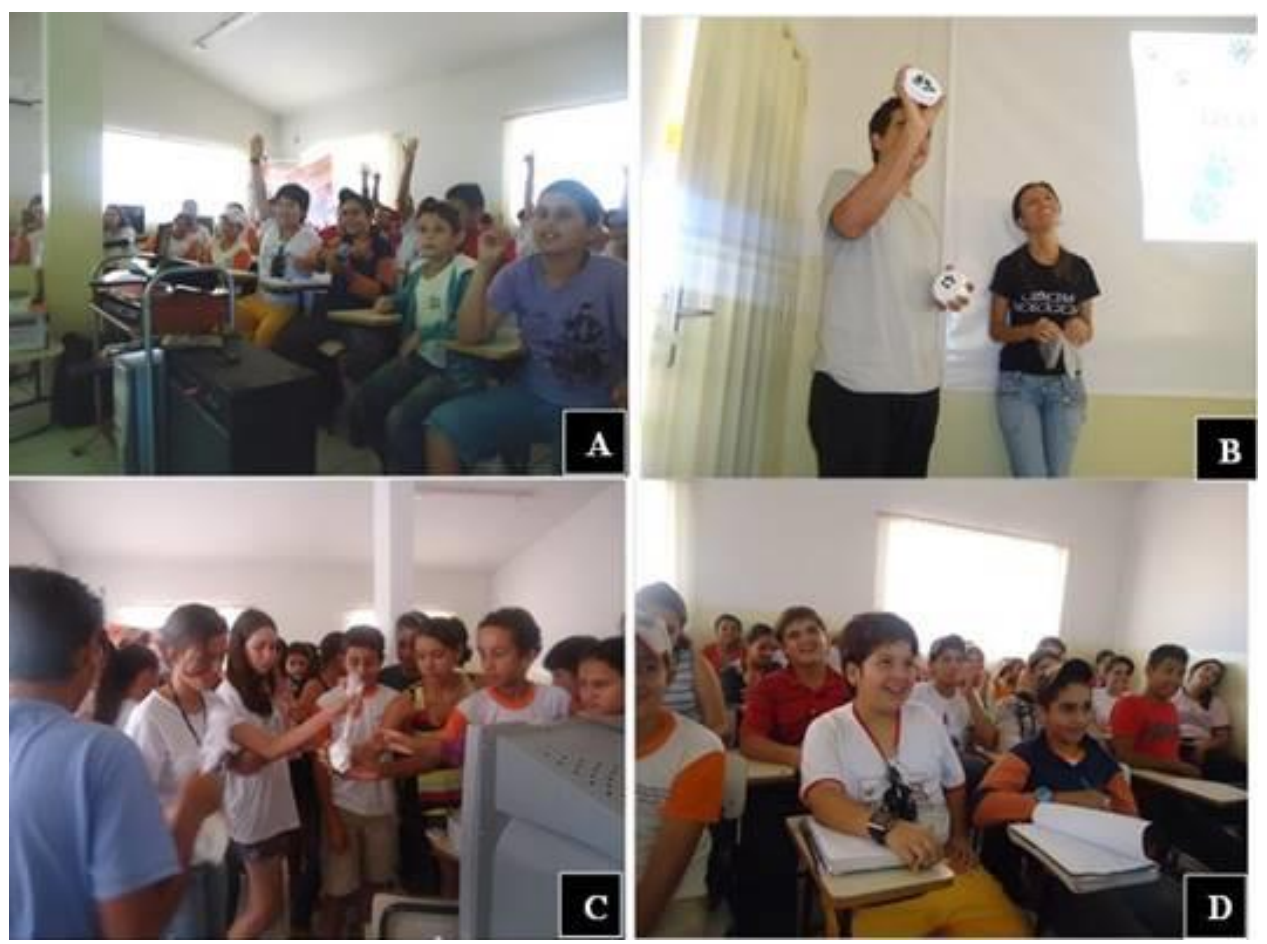

Figura 4: Realização das oficinas na escola campo. (A, C e D) Alunos do ensino fundamental participantes do estudo; (B) Apresentação dos moldes confeccionados a partir de material reciclado aos alunos. Fonte: os autores. 


\section{Conclusões}

Com a realização deste estudo, foi possível utilizar os moldes e contramoldes de pegadas como materiais pedagógicos. Conclui-se que estes modelos facilitaram o aprendizado e a inclusão social. Pode-se inferir ainda que este projeto possibilitou reflexões críticas entre os alunos e contribuiu para a formação de cidadãos ambientalmente responsáveis. Além de todas as vantagens apresentadas este material produzido ainda poderá ser utilizado como material didático para crianças com deficiência visual, contribuindo assim para a inclusão social na escola.

\section{AGRADECIMENTOS}

Ao Biólogo Marcos Vinicius Gomes Leite, pela disposição e condução á escola campo, a PROGRAD/UFG pela concessão da bolsa PROLICEN ao primeiro autor, a Sefac (Serra do Facão Energia SA.) pelo apoio logístico.

\section{REFERÊNCIAS}

AGUIAR, L.M.S.; MACHADO, R.B.; MARINHO-FILHO, J. A diversidade biológica do Cerrado. pp. 17- 40. In: AGUIAR, L.M.S.; CAMARGO, A.J.A. Cerrado: ecologia e caracterização. Planaltina: Embrapa Cerrados; Brasília: Embrapa Informação Tecnológica, 2004.

BECKER, M.; DALPONTE, J. C. Rastros de Mamíferos Silvestres Brasileiros. $2^{\text {a }}$ ed. Brasília: Editora UnB, 1999.

BENITES, M.; MAMEDE S.B. Mamíferos e aves como instrumentos de educação e conservação ambiental em corredores de biodiversidade do Cerrado, Brasil. Mastozoología Neotropical, v. 15, n. 2, p.261-271, 2008.

BERLINCK, C.N.; LIMA; L.H. A. Identificação de rastro de animais, Educação Ambiental e valorização da fauna local no entorno do Parque Estadual de Terra Ronca (GO). Revista eletrônica do mestrado em Educação Ambiental. v. 18, p. 174-189, 2007.

CARVALHO, I.C.M. Educação Ambiental: a formação do sujeito ecológico, $3^{\text {a }}$ ed. São Paulo: Cortez, 2008, 256p.

CARVALHO Jr., O.; LUZ, N.C. Pegadas: Série Boas Práticas, v. 3, Belém: EDUFPA, 2008. 64p.

COOLEY, H.S.; WIELGUS, R.B.; KOEHLER, G.M.; ROBINSON, H.S.; MALETZKE, B.T. Does hunting regulate cougar populations? A test of the compensatory mortality hypothesis. Ecology, v. 90, n.10, p. 2913-2921, 2009.

DAMASCENO, M.N.; BESERRA, B. Estudos sobre educação rural no Brasil: estado da arte e perspectivas. Educação Pesquisa, São Paulo, v. 30, n. 1, 2004. 
FEINSINGER P. El Diseño de Estudios de Campo para la Conservación de la Biodiversidad. Santa Cruz de la Sierra, Bolívia, Editoral FAN (Fundación Amigos de la Naturaleza), 2004.

FERREIRA, B.M. (Org.). Guia de fauna: Usina hidrelétrica Serra do Facão. 1a ed. Pires do Rio: Editora Pires do Rio, 111p., 2010.

FIGUEIRA, J.E.C.; BARBOSA, M.M. KRETTLI, L.G. No rastro de quem ainda resta: Educação Ambiental para alunos do ensino fundamental da APA Caste de Lagoa Santa, Minas Gerais. Anais do $7^{\circ}$ Encontro de Extensão da UFMG, Belo Horizonte. 2004.

FREITAS, L.A.M.; BARROSO H.F.D.; RODRIGUES H.G.; AVERSI-FERREIRA T.A. Construção de modelos embriológicos com material reciclável para uso didático. Bioscience Journal, Uberlândia, v. 24, n.1, p. 91-97, 2008.

GRELLE, C.E.V., PAGLIA, A.P.; SILVA, H.S. Análise dos fatores de ameaça de extinção: estudo de caso com os mamíferos brasileiros. In: ROCHA, C.F.D. (Org.). Biologia da conservação: essências, Rima editora, São Carlos-SP, 2006. $588 \mathrm{p}$.

LEMOS, F.G.; K.G. FACURE; F.C. AZEVEDO. A first approach the comparative ecology of the hoard Fox and the crab-eating Fox in a fragmented human altered landscape in the Cerrado biome at Central Brazil. In: ROSALINO, L.M.; GHELER-COSTA C., (Eds). Middle-Sized Carnivores in Agricultural Landascapes. New York: Nova Science Publishers, p. 143-160, 2011.

MACHADO, R.B.; RAMOS NETO, M.B.; PEREIRA, P.G.P.; CALDAS, E.; GONÇALVES, D.A.; SANTOS,,N.S.; TABOR, K.; STEININGER, E.M. Estimativas de perda da área do Cerrado brasileiro. Brasília: Conservação Internacional. 2004 (Relatório técnico não publicado).

MYERS N.; MITTERMEIER, R.A.; MITTERMEIER, C.G.; FONSECA, G.A.B.; KENT J. Biodiversity hotspots for conservation priorities. Nature, v.403, n.6772, p. 853-858, 2000.

SCOSS, L. M.; MARCO JUNIOR, P.; SILVA, E.; MARTINS, S. V. Uso de parcelas de areia para o monitoramento de impacto de estradas sobre a riqueza de espécies de mamíferos. Revista Árvore, Viçosa-MG, v. 28, n.1, p. 121-127, 2004.

TRIVELATO, S.L.F. O Currículo de Ciências e a Pesquisa em Educação Ambiental. Educação: Teoria e Prática. Rio Claro-SP, v. 9, n.16/17, p. 57-61, 2001. 